\title{
Lung cancer, treatment and nutritional status
}

\author{
MARIA PILIKIDOU $^{1,2}$, FOTEINI PALYVOU ${ }^{1}$, SOUSANA K. PAPADOPOULOU ${ }^{1}$, \\ THEODORA TSIOUDA ${ }^{2}$, EIRINI TSEKITSIDI ${ }^{1}$, KONSTANTINA ARVANITI $^{2}$, ANGELIKI MIZIOU $^{2}$, \\ ZOI TSINGERLIOTI ${ }^{2}$, GEORGIOS APOSTOLIDIS ${ }^{2}$, ROMANOS NTILOUDIS ${ }^{2}$, KONSTANTINA BONIOU ${ }^{2}$, \\ ATHANASIOS A. TSIOUDAS ${ }^{1}$, ANGELIKI CHEVA ${ }^{3}$, DIMITRIS PETRIDIS ${ }^{4}$ and PAUL ZAROGOULIDIS ${ }^{5}$ \\ ${ }^{1}$ Department of Nutritional Sciences and Dietetics, Faculty of Health Sciences, International Hellenic University, \\ 54623 Thessaloniki; ${ }^{2}$ Pulmonary-Oncology Department, 'Theageneio' Cancer Hospital, 54007 Thessaloniki; \\ ${ }^{3}$ Pathology Department, Faculty of Medicine, Aristotle University of Thessaloniki, University Campus, 54124 Thessaloniki; \\ ${ }^{4}$ Department of Food Science and Technology, School of Geosciences, International Hellenic University, \\ 57400 Thessaloniki; ${ }^{5}$ Pulmonary Department, 'Bioclinic' Private Hospital, 54622 Thessaloniki, Greece
}

Received December 23, 2020; Accepted September 24, 2021

DOI: $10.3892 / \mathrm{mco} .2021 .2410$

\begin{abstract}
Lung cancer is often diagnosed at inoperable advanced stages, and most patients exhibit cancer cachexia. The nutritional status of patients has been previously observed to serve a key role in cancer survival and cancer surgery. The aim of the current study was to collect information regarding the treatment of patients and associate them with different nutritional measurements. A total of 82 patients with non-small cell lung cancer were included in the present study. Several parameters were assessed, such as body mass index (BMI), Mediterranian diet score, number of years spent smoking, basic metabolsim (RMR; $\mathrm{kcal} /$ day), $\mathrm{VO}_{2}(\mathrm{ml} / \mathrm{min})$, ventilation (lt $/ \mathrm{min})$ and physical activity. All the aforementioned parameters were associated with patient treatment, nutritional status and survival. Two-way ANOVA was conducted and pairwise group mean differences were tested using Fisher's LSD and Tukey tests. Normality and variance homogeneity was checked in all cases. The results revealed that RMR and oxygen consumption were negatively affected by the survival status of patients $(\mathrm{P}=0.012$ and $\mathrm{P}=0.043$, respectively). The mean fat difference was higher in patients treated with immunotherapy, and lower in those treated with chemotherapy in addition to immunotherapy, as demonstrated by Tukey comparisons. The survival of 25 patients were affected by the treatment they received $(\mathrm{P}=0.006)$. Chemotherapy administered in addition to immunotherapy prolonged patient life almost two-fold when compared with the individual effects of the two treatments, which became equal according to Fisher's LSD comparisons.
\end{abstract}

Correspondence to: Dr Paul Zarogoulidis, Pulmonary Department, 'Bioclinic' Private Hospital, 86 Mitropoleos Street, 54622 Thessaloniki, Greece

E-mail: pzarog@hotmail.com

Key words: non-small cell lung cancer, nutrition, basic metabolism, chemotherapy, immunotherapy, body mass index
In conclusion, the nutritional status of patients was associated with the administration of chemotherapy in addition to immunotherapy, and patient survival. Increased metabolism and fat mass were also associated with prolonged survival.

\section{Introduction}

Lung cancer is usually diagnosed at a late stage due to lack of early disease symptoms. Currently we are trying to direct all high risk patients to have computed tomography scans of the thorax with low dose radiation (1). We have novel tools for diagnosis such as the radial endobronhial ultrasound, endobronchial ultrasound with convex probe, electromagnetic navigation and ARCHIMEDES ${ }^{\circledR}$ fused navigation system. Moreover; we can perform transthoracic biopsy with convex probe or computed tomography guided biopsies (2-7). Currently we have several treatments for non-operable non-small cell lung cancer (NSCLC) with chemotherapy, radiotherapy, tyrosine kinase inhibitors, immunotherapy or combinations (8-11).

Moreover; after we acquire biopsy we investigate for the following gene expressions growth factor receptor (EGFR) or T790M, anaplastic lymphoma kinase (ALK), Programmed death-ligand 1 (PD-L1), Proto-oncogene tyrosine-protein kinase ROS-1, RET proto-oncogene encodes and proto-oncogene B-Raf $(9,12)$. All these treatments of course have their adverse effects that the treating physician has to overcome $(13,14)$.

Moreover; usually patients upon diagnosis have recently lost weight and have cancer cachexia. All patients which are going to receive chemotherapy or radiotherapy must have good nutritional status. It has been previously observed that cachexia is an important independent factor for survival and treatment efficiency (15). It is known that malnutrition frequently coexists in cancer patients. Several studies demonstrated that the incidence of malnutrition among cancer patients can be up to $31-97 \%(16,17)$. Most studies have been done in gastrointestinal tumors and very few in lung cancer patients. Xara et al (18) observed that the incidence of malnutrition among patients with non-small-cell lung cancer is up to $35.7 \%$. The consequences of 
malnutrition may reduce immune function, decrease treatment response, increase infection rates, and tolerance to treatment, lower quality of life, increase health care costs, and reduce survival time $(19,20)$. Moreover; the relative risk of death from malnutrition was observed to be 1.8 times higher for cancer patients without malnutrition (21). It is absolutely important that the nutritional status of cancer patients is included in the treatment management, since it decides the patient's tolerance for curative treatment (22). Nutritional support will maintain current health status but also, will improve patient satisfaction, quality of life, and treatment outcomes.

Malnutrition has been observed to be prevalent in advanced lung cancer patients. These patients require timely nutrition support and guidance, management of treatment symptoms mainly with drug interventions. Regarding lung cancer, the nutritional status of patients with advanced lung cancer, particularly those at a higher risk of malnutrition, such as elderly patients, female patients, smokers, poor nutritional status has been associated with worse clinical outcome. Moreover; patients with malnutrition should be given more attention; their nutritional status should be evaluated and re-evaluated at least after 2 months and they should be given nutritional support in time. It is known that in almost all patients taste is altered and nausea is observed, especially in chemotherapy treatment. There are special tools to evaluate these alterations.

Improvement of the nutritional status of patients with advanced lung cancer may have beneficial effects on their quality of life and treatment effectiveness. The same has been observed with chronic obstructive pulmonary disease (COPD) (23). We investigated in our study non-small cell lung cancer patients and recorded several body and metabolism characteristics and associated them with treatment benefit and survival.

\section{Patients and methods}

Patients. We collected data from 82 NSCLC patients stage IV. Our study was conducted in the 'Theageneio' Cancer Hospital, Thessaloniki, Greece. Our study was also approved by our investigational review board ('Theageneio' Cancer Hospital, Thessaloniki, Greece) and was performed according to the principles of the Declaration of Helsinki. Written informed consent was acquired from the patients. All patients were diagnosed and had first line treatment. Patients cheracteristics were as follows: 40 adenocarcinomas, 42 squamous cell carcinoma, 40 male, 42 female, Male mean age 65, Female mean age 62 . The only criteria was all newly diagnosed patients at that time point where our study was initiated. Patients received chemotherapy, immunotherapy, radiotherapy or combination of these treatments. Several data for all patients were recorded upon the first day of diagnosis and last follow up. In specific: Survival, treatment, weight, height, age, body mass index (BMI), waist and hips length, waist/hip ratio (WHR), lean body mass, total body water, extracellular water, intracellular water, body cell mass (BCM), basic metabolism (RMR), Harris Benedict (\%Pred), $\mathrm{VO}_{2}(\mathrm{ml} / \mathrm{min}), \mathrm{Ve}(\mathrm{lt} / \mathrm{min})$, VarVe (\%), VarVO 2 (\%), Rf (1/min), $\mathrm{FeO}_{2}(\%)$, Mediterranean diet score, physical activity level and number of years spent smoking.
Statistical procedure. Regarding survival, it was represented as the time of diagnosis and death or last follow up. The BMI is a measure used to determine obesity. It is the ratio of weight to the square of a person's height. BMI $<18.5$ indicates that the person is underweight 18.5-24.9 indicates that the person is normal weight 25-29.9 indicates that the person is overweight $>30$ indicates that the person is obese. The WHR shows the relative distribution of fat in adults and the risk of disease. It is the ratio of the waist circumference $(\mathrm{cm})$ to the hip circumference $(\mathrm{cm})$. WHR is strongly associated with visceral (or abdominal) obesity, which significantly increases the likelihood of developing chronic diseases such as cardiovascular disease and type II diabetes. Increased risk when WHR >1.0 (in men). Total body water; the ideal percentage for adult men is $50-65 \%$. BCM $(\mathrm{kg})$; the total mass of cellular elements in the body that make up the whole of metabolically active tissue. There is a depletion of BCM that is characteristic of chronic conditions such as AIDS and end-stage cancer. RMR (kcal/day); basic metabolism (RMR) is the calories consumed by the body at rest for its basic vital functions. Harris Benedict (\%Pred); the percentage of RMR, obtained from the Harris Benedict equation. $\mathrm{VO}_{2}(\mathrm{ml} / \mathrm{min})$; the volume $(\mathrm{ml})$ of oxygen consumed per minute. Ve (lt $/ \mathrm{min})$; ventilation is the volume of air that is exhaled from the lungs over a period of one minute. The normal adult at rest breathes about 5-10 1/min. VarVe (\%); the percentage variance of $\mathrm{Ve}$. $\mathrm{VarVO}_{2}(\%)$; the percentage of the average $\mathrm{VO}$ variation. $\mathrm{Rf}(1 / \mathrm{min})$; respiratory frequency is the number of breaths per minute. Normal Rf for healthy adults is between 12 and 20 breaths per minute. $\mathrm{FeO}_{2}(\%)$; the concentration of OD in the exhaled air. Mediterranean diet score; this score ranges from 0-55 and results from a questionnaire of 11 questions about the frequency of food consumption, which assesses adherence to the Mediterranean diet and the risk of heart disease. The higher the score, the greater the attachment to the Mediterranean diet. 0-20: Low attachment, 21-35: Moderate attachment and 36-55: High attachment (All patients said that they did not change anything in their eating habits from the first to the second measurement). Physical activity level; Level of physical activity evaluated through 8 questions and patients were categorized into 3 categories: i) Low, ii) moderate and iii) high physical activity (also all patients said that they did not change anything in their physical activity from the first to the second measurement). Number of years spent smoking; 'Pack years' is a clinical quantification of smoking used to measure a person's exposure to tobacco. It is the product of the packs of cigarettes smoked during the day the smoking years.

Patients were subjected to various treatments such as chemotherapy (chemo) or immunotherapy (immune), a combination of those (combo) and finally radiation treated in combination with either one as previously explained or combined additionally with drug administration (radiation+). Under the four treatment regimens, patients were additionally cross-tabulated with their survival status. The Kaplan-Meier survival rates were also produced and differences among groups were examined using log-rank and Kruskal-Wallis test. The well-being of patients was recorded in two periods, the initial commenced upon diagnosis and the final date upon death or last follow-up, measuring at that interval the weight, fat, lean and BMI, relative metabolic rate RMR and breath 
index $\left(\mathrm{VO}_{2}\right)$. Their response, treated as paired final minus initial difference, was questioned to reflect the impact of survival status and treatment type, thus a two-factor analysis of variance (ANOVA) was conducted. Pairwise group mean differences were tested via Tukey method. Normality and variance homogeneity was checked in all cases.

\section{Results}

Survival status and treatment type. Table I shows the cross-tabulation between survival status and treatment type. Interestingly, only one death was recorded when immunotherapy interacted with, whereas the survival ratio was greater in patients treated with radiation+ (24/8) although not statistically supported. Few patients were combo treated (13.41\%) reasonably putting under question for possible synergistic results. The lack of observations in the cell immune-death did not permit us to include the interaction term in ANOVA due to possible errors in the calculation of sum of squares.

The combined effect of chemotherapy and immunotherapy revealed higher survival rates as Kaplan-Meier graph clearly indicated (Fig. 1), supported also by the statistically significantly result of log-rank $(\mathrm{P}=0.0053)$ and Kruskal-Wallis test $(\mathrm{P}=0.007)$ in Tables II and III. Patients treated with the combined protocol increased 2.5 times higher their mean survival rate (828.75) as compared to those treated with chemotherapy (337.75) and 1.6 times to those treated with radiation+ (510). Considering the median survival time, the above multipliers are reformed to 1.76 (670 days vs. 380.5) and 1.97670 vs. 339.5) respectively.

Data were further investigated using one-factor ANOVA (treatment effect) on the log survival days.

Survival. The survival days of 25 patients (recorded as dead) were affected by the treatment type $(\mathrm{P}=0.006)$ in a way as shown in Fig. 2.

The combo treatment prolongs the patients' life nearly double as compared to the chemotherapy and radiation+ therapy (761 days vs. 418 and 318, in antilog values), whose effects become equal on surviving according to Fisher's LSD comparisons (Table IV). The mean metabolic rate RMR was higher in the initial stage of study (117.8\% vs. $110.3 \%)$ but the mean breath index was found similar between stages (10.0\% vs. $10.3 \%)$.

Parameters. The parameters RMR and breath condition were negatively affected by the survival status $(P=0.012$ and 0.043 , respectively). Fig. 3 reveals an abrupt drop of RMR mean difference for the survived group (-217.9), probably as a result of stressed conditions subjected to patients under therapy.

In a similar manner, breath index was deteriorated in the survived group (-30.2) as Fig. 4 illustrates so, resulting presumably from the adverse effects of treatments operation.

The treatment effect was significantly present $(\mathrm{P}=0.044)$ only on the fat condition of patients (Fig. 5). Although the mean fat $\%$ in the patients was similar in both stages (initial $27.9 \%$ and final $28.6 \%$ ), mean fat difference was higher and positive in the patients treated with immunity and lower and negative for those combo treated as as Tukey's mean comparisons
Table I. Cross-tabulated data according to survival status and treatment type.

\begin{tabular}{lrrrc}
\hline Treatment & 0 & 1 & All & $\%$ \\
Chemotherapy & 8 & 10 & 18 & 21.95 \\
Combined & 8 & 13 & 21 & 13.41 \\
Immunotherapy & 1 & 10 & 11 & 25.61 \\
Radiation+ & 8 & 24 & 32 & 39.02 \\
All & 25 & 57 & 82 & 100.00 \\
Percentage of & 30.48 & 69.52 & & \\
patients & & & & \\
receiving & & & & \\
treatment & & & & \\
\hline
\end{tabular}

0 and 1 indicates a survival status of alive and dead, respectively. Combined treatment refers to chemotherapy administered in addition to immunotherapy. Radiation+, radiation therapy combined with chemotherapy.

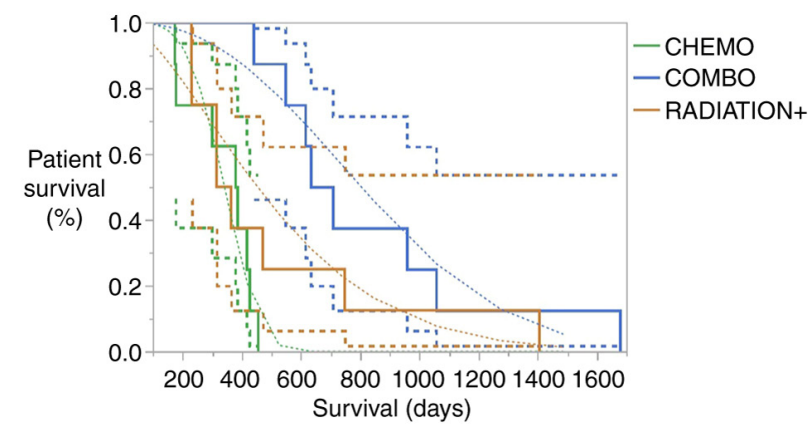

Figure 1. Kaplan-meier survival rates with $95 \%$ confidence limits in accordance with treatment effects. Chemo, chemotherapy; Combo, combined; Radiation+, radiation therapy combined with chemotherapy.

demonstrate in Table V. Radiation+ and chemotherapy did not clearly differentiated among treatments due to letters overlap in the table.

\section{Discussion}

It has been clinically observed that advanced lung cancer patients experience various degrees of weight loss. During a six month period of time severe weight loss was observed in $7 \%$ of the patients (weight loss of $>10 \%$ in 1 month or $>20 \%$ in 6 months). Most of cancer patient survivors keep losing weight after six months although they are under treatment. Usually continuous weight loss indicates poor treatment response and finally contributes to mortality in lung cancer $(24,25)$. It is absolutely important that the nutritional status of cancer patients is included in the treatment management, since it decides the patient's tolerance for curative treatment (22).

Nutritional support will maintain current health status but also, will improve patient satisfaction, quality of life, and treatment outcomes. Malnutrition has been observed to be prevalent in advanced lung cancer patients. These patients require timely nutrition support and guidance, management of treatment symptoms, with drug interventions. There was a 
Table II. Parametric and quantile data of survival time according to treatment effects.

\begin{tabular}{|c|c|c|c|c|c|c|c|c|c|}
\hline \multirow[b]{2}{*}{ Group } & \multicolumn{4}{|c|}{ Parametric data } & \multicolumn{5}{|c|}{ Quantiles } \\
\hline & $\begin{array}{l}\text { Number } \\
\text { failed }\end{array}$ & $\begin{array}{l}\text { Number } \\
\text { censored }\end{array}$ & $\begin{array}{l}\text { Mean } \\
\text { (days) }\end{array}$ & $\begin{array}{c}\text { Standard } \\
\text { error }\end{array}$ & $\begin{array}{c}\text { Median } \\
\text { time (days) }\end{array}$ & $\begin{array}{c}\text { Lower } \\
95 \%\end{array}$ & $\begin{array}{l}\text { Upper } \\
95 \%\end{array}$ & $\begin{array}{l}25 \% \\
\text { Failures }\end{array}$ & $\begin{array}{c}75 \% \\
\text { Failures }\end{array}$ \\
\hline Chemotherapy & 8 & 0 & 337.75 & 39.221 & 380.5 & 172 & 425 & 237.0 & 420.5 \\
\hline Combined & 8 & 0 & 828.75 & 141.305 & 670.0 & 439 & 1,056 & 580.5 & $1,006.5$ \\
\hline Radiation+ & 8 & 0 & 510.00 & 141.079 & 339.5 & 230 & 748 & 273.0 & 609.5 \\
\hline
\end{tabular}

Combined treatment refers to chemotherapy administered in addition to immunotherapy. Radiation+, radiation therapy combined with chemotherapy.

Table III. Between group test data of survival time according to treatment effects.

\begin{tabular}{lrcc}
\hline Test & $\chi^{2}$ & DF & Prob $>\chi^{2}$ \\
\hline Log-rank & 10.4696 & 2 & 0.0053 \\
Kruskal-Wallis & 9.9218 & 2 & 0.0070 \\
\hline
\end{tabular}

DF, degrees of freedom; Prob, exact probability value.

Table IV. Grouping information using the Fisher's LSD on treatment type and mean survival ( $\log _{10}$ values).

\begin{tabular}{lllll}
\hline Treatment & $\mathrm{N}$ & Mean & \multicolumn{2}{c}{ Grouping } \\
\hline Combined & 8 & 2.881 & $\mathrm{~A}$ & - \\
Radiation+ & 8 & 2.6222 & - & $\mathrm{B}$ \\
Chemotherapy & 8 & 2.5026 & - & $\mathrm{B}$
\end{tabular}

Combined treatment refers to chemotherapy administered in addition to immunotherapy. Means that do not share a letter are significantly different $(\mathrm{P}<0.05)$. Radiation+, radiation therapy combined with chemotherapy.

Table V. Grouping information using the Tukey test on treatment type and mean fat difference (final minus initial).

\begin{tabular}{lcccc}
\hline Treatment & $\mathrm{N}$ & Mean & \multicolumn{2}{c}{ Grouping } \\
\hline Immunotherapy & 11 & 3.18 & $\mathrm{~A}$ & - \\
Chemotherapy & 18 & 2.31 & $\mathrm{~A}$ & $\mathrm{~B}$ \\
Radiation+ & 32 & 0.48 & $\mathrm{~A}$ & $\mathrm{~B}$ \\
Combined & 21 & -1.16 & - & $\mathrm{B}$ \\
\hline
\end{tabular}

Combined treatment refers to chemotherapy administered in addition to immunotherapy. Means that do not share a letter are significantly different $(\mathrm{P}<0.05)$. Radiation+, radiation therapy combined with chemotherapy.

study where $58.8 \%$ of the patients had difficulty with eating food, including $6.5 \%$ who could consume food only in puree

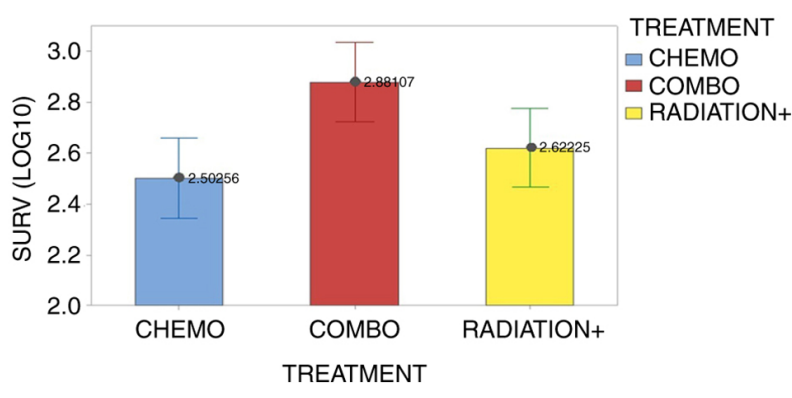

Figure 2. Effect of treatment type on the mean survival patients ( $\log _{10}$ transformation). Vertical bars denote the $95 \%$ confidence intervals of the means based on the error mean square of ANOVA. The pooled standard deviation was used to calculate intervals. Chemo, chemotherapy; Combo, combined; Radiation+, radiation therapy combined with chemotherapy.

form and $2.2 \%$ who could consume food only in liquid form. Many cancer patients with advanced lung cancer have been consuming diets that would likely be insufficient to maintain weight even in healthy individuals. Results from recent studies presented data where 61.8 to $11.7 \%$ of the patients had a reduction in fat. It has been observed that patients with lung cancer which have higher consumption of protein and fat, which could lead to increased weight loss.

It is known that increased weight loss may result in increased rate of complications; impaired wound healing; reduced immune function, and decreased tolerance to surgery, radiotherapy, and of course chemotherapy. Most importantly reduced quality of life $(26,27)$. More than $82.8 \%$ of the advanced lung cancer patients have nutrition impact symptoms, appetite loss, vomiting, including nausea or fullness $(9.1 \%)$, choking (57.2\%), and diarrhea (59.0\%). In all cases these symptoms are disease related by advanced lung cancer. In our study the most important factors affecting survival and treatment efficiency were fat, $\mathrm{RMR}$ and $\mathrm{VO}_{2}$ consumption. Meaning that patients with severe emphysema (COPD) and cachexia upon diagnosis had the worst survival and treatment efficiency due to their low cell metabolism. Our findings agree with previous studies in the field. In our study we included more parameters than other studies, however; our main findings remain the same.

The sooner a patient is diagnosed with low tumor burden, the higher the survival will be (28-32). Early stage lung cancer patients have by definition low tumor burden since the main lesion is $\leq 3 \mathrm{~cm}$ and infiltrated lymphnodes are N0-N1 disease. 


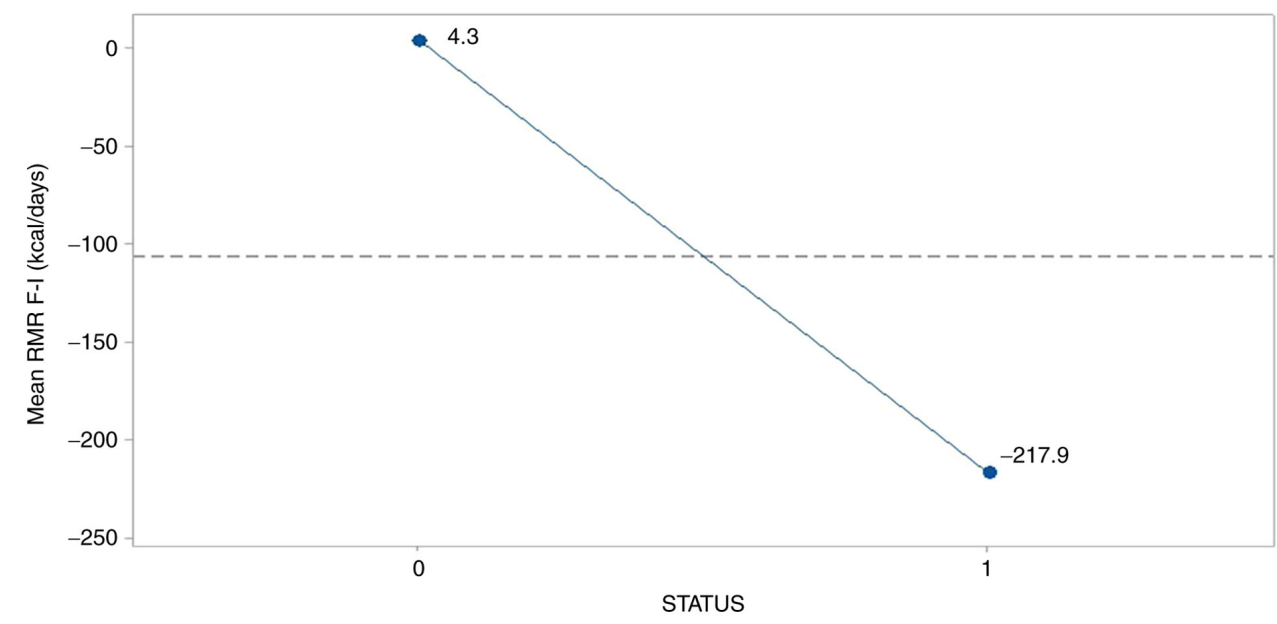

Figure 3. Effect of survival status on mean relative metabolic rate. 0 , female; 1 , male.

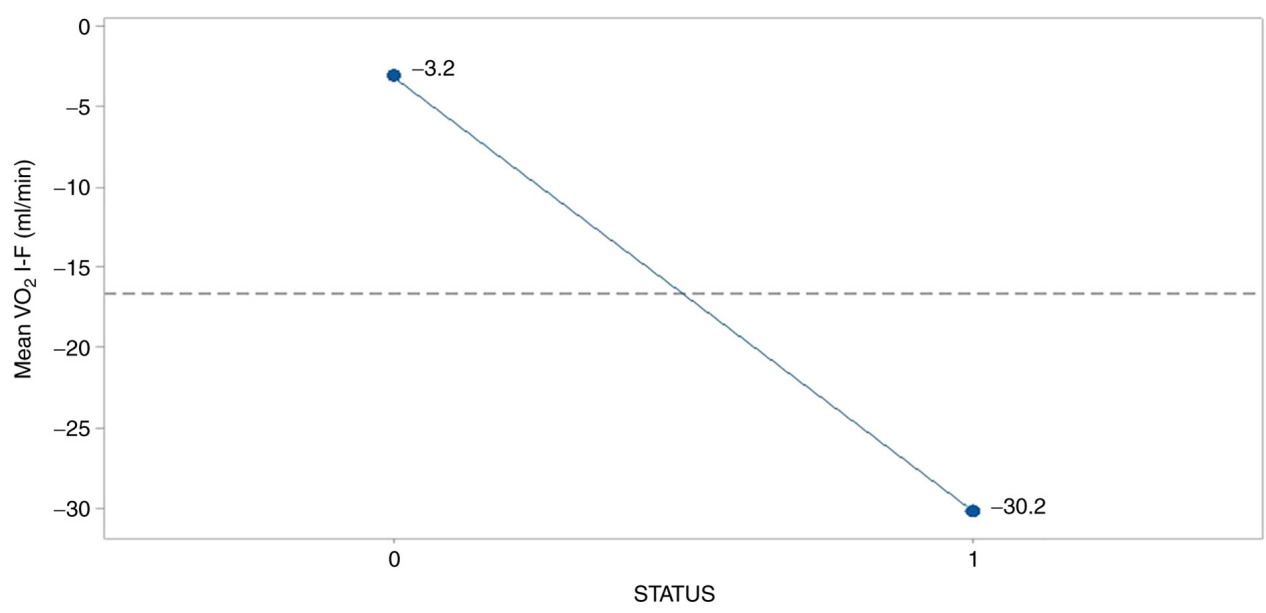

Figure 4. Effect of survival status on the mean breath index. 0, female; 1, male.

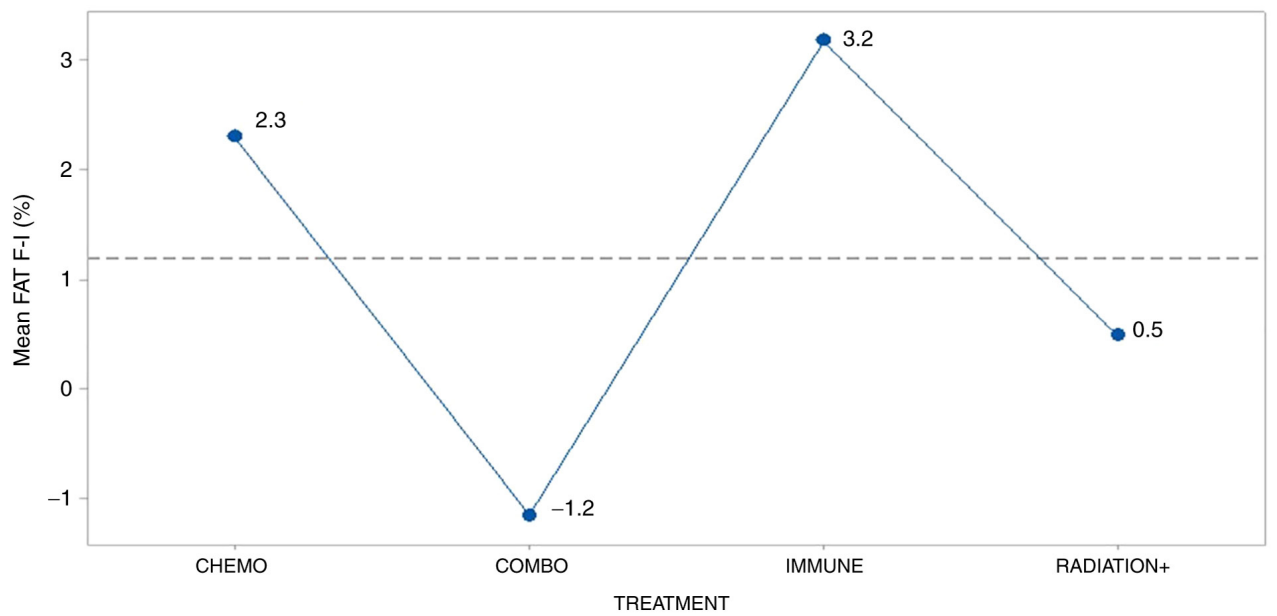

Figure 5. Effect of treatment type on the mean fat difference. Vertical bars denote the $95 \%$ confidence intervals of means based on the error mean square of ANOVA. Radiation+, radiation therapy combined with chemotherapy.

Non-operable patients usually have a main lesion $\geq 3 \mathrm{~cm}$ with several infiltrated lymphnode stations N2-N3 disease or evan distant metastasis. Therefore the extended tumor burden consumes several nutritional elements in different parts of the body and cachexia is extensive. We should focus on adding supplements and special nutrition to these patients. In our study we investigated the following parameters for the first time RMR (basic metabolism), \%Pred (Harris Benedict), 
$\mathrm{VO}_{2}(\mathrm{ml} / \mathrm{min}), \mathrm{Ve}(\mathrm{lt} / \mathrm{min}), \operatorname{VarVe}(\%), \operatorname{VarVO}_{2}(\%), \operatorname{Rf}(1 / \mathrm{min})$, $\mathrm{FeO}_{2}(\%)$, Mediterranean diet score, physical activity level and we believe data and information should be included as they are currently. We believe that the additional measurements that we included enlighten more aspects of lung cancer cachexia. Moreover, we enlightened the association between lung cancer cachexia and treatment benefit. The RMR which is the basic metabolism was found to be lower in the survivors because the survivors have depleted their fat and muscle reservoir (cachexia). These factors are associated directly with the metabolism of a patient.

Our findings agree with previous studies. However; since we have investigated different treatments, our new findings are mostly with immunotherapy patients. In conclusion, the combined treatment with chemotherapy and immunotherapy is a superior protocol for prolonging (twice) the survival rate and reducing the fat condition of patients. On the other hand, Harris Benedict RMR\% and breath condition $\left(\mathrm{VO}_{2}\right)$ were found distantly lower in the survivors.

Major limitation of our study is the small number of patients and that all patients recruited were only lung cancer patients. Moreover; patients received different types of treatment, therefore the number of patients for each treatment was even smaller. In conclusion, the combined treatment with chemotherapy and immunotherapy appears a superior protocol for prolonging (twice) the survival rate and reducing the fat condition of patients. On the other hand, Harris Benedict RMR\% and breath condition $\left(\mathrm{VO}_{2}\right)$ were found distantly lower in the survivors. Moreover; Our study included the findings from previous studies, but also added novel measurements such as: RMR (basic metabolism), \% Pred (Harris Benedict), $\mathrm{VO}_{2}(\mathrm{ml} / \mathrm{min}), \operatorname{Ve}(\mathrm{lt} / \mathrm{min}), \operatorname{VarVe}(\%), \operatorname{VarVO}_{2}(\%), \operatorname{Rf}(1 / \mathrm{min})$, $\mathrm{FeO}_{2}(\%)$, Mediterranean diet score, physical activity level and we believe data and information should be included as they are currently. We believe that the additional measurements that we included enlighten more aspects of lung cancer cachexia. Moreover, we enlightened the association between lung cancer cachexia and treatment benefit. The RMR which is the basic metabolism was found to be lower in the survivors because the survivors have depleted their fat and muscle reservoir (cachexia). The $\mathrm{VO}_{2}$ consumption was also found to be lower in lung cancer survivors because of COPD status and disease within the lung, most of these patients used oxygen supplement due emphysema and lung cancer disease. Moreover, this is the first study to include different treatment options.

\section{Acknowledgements}

Not applicable.

\section{Funding}

No funding was received.

\section{Availability of data and materials}

The datasets used and/or analyzed during the current study are available from the corresponding author on reasonable request.

\section{Author's contributions}

MP, FP, SP, TT, ET, KA, AM, ZT, GA, RN, KB, AAT, AC, $\mathrm{DP}$ and $\mathrm{PZ}$ collected the data and wrote the manuscript. DP and PZ performed the statistics analysis. All authors read and approved the final manuscript. PZ, DP and TT confirm the authenticity of the raw data.

\section{Ethics approval and consent to participate}

The current study was conducted in the 'Theageneio' Cancer Hospital, Thessaloniki, Greece and was approved by the investigational review board of ('Theageneio' Cancer Hospital, Thessaloniki, Greece) and was performed according to the principles of the Declaration of Helsinki. Written informed consent was acquired from the patients.

\section{Patient consent for publication}

Not applicable.

\section{Competing interests}

The authors declare that they have no competing interests.

\section{References}

1. Choi HK and Mazzone PJ: Lung cancer screening. Surg Oncol Clin N Am 29: 509-524, 2020.

2. Zaric B, Stojsic V, Sarcev T, Stojanovic G, Carapic V, Perin B, Zarogoulidis P, Darwiche K, Tsakiridis K, Karapantzos I, et al: Advanced bronchoscopic techniques in diagnosis and staging of lung cancer. J Thorac Dis 5 (Suppl 4): S359-S370, 2013.

3. Zaric B, Stojsic V, Carapic V, Kovacevic T, Stojanovic G, Panjkovic M, Kioumis I, Darwiche K, Zarogoulidis K, Stratakos G, et al: Radial endobronchial ultrasound (EBUS) guided suction catheter-biopsy in histological diagnosis of peripheral pulmonary lesions. J Cancer 7: 7-13, 2016.

4. Darwiche K, Zarogoulidis P, Baehner K, Welter S, Tetzner R, Wohlschlaeger J, Theegarten D, Nakajima T and Freitag L: Assessment of SHOX2 methylation in EBUS-TBNA specimen improves accuracy in lung cancer staging. Ann Oncol 24: 2866-2870, 2013.

5. Oezkan F, Khan A, Zarogoulidis P, Hohenforst-Schmidt W, Theegarten D, Yasufuku K, Nakajima T, Freitag L and Darwiche K: Efficient utilization of EBUS-TBNA samples for both diagnosis and molecular analyses. Onco Targets Ther 7: 2061-2065, 2014.

6. Sapalidis K,Zarogoulidis P, Petridis D, Kosmidis C, Fyntanidou B, Tsakiridis K, Maragouli E, Amaniti A, Giannakidis D, Koulouris C, et al: EBUS-TNBA 22G samples: Comparison of PD-L1 expression between DAKO and BIOCARE ${ }^{\circledR}$. J Cancer 10: 4739-4746, 2019

7. Boskovic T, Stanic J,Pena-Karan S, Zarogoulidis P, Drevelegas K, Katsikogiannis N, Machairiotis N, Mpakas A, Tsakiridis K, Kesisis G, et al: Pneumothorax after transthoracic needle biopsy of lung lesions under CT guidance. J Thorac Dis 6 (Suppl 1): S99-S107, 2014.

8. Domvri K, Darwiche K, Zarogoulidis P and Zarogoulidis K: Following the crumbs: from tissue samples, to pharmacogenomics, to NSCLC therapy. Transl Lung Cancer Res 2: 256-258, 2013.

9. Domvri K, Zarogoulidis P, Darwiche K, Browning RF, Li Q, Turner JF, Kioumis I, Spyratos D, Porpodis K, Papaiwannou A, et al: Molecular targeted drugs and biomarkers in NSCLC, the evolving role of individualized therapy. J Cancer 4: 736-754, 2013.

10. Zarogoulidis K, Zarogoulidis P, Darwiche K, Boutsikou E, Machairiotis N, Tsakiridis K, Katsikogiannis N, Kougioumtzi I, Karapantzos I, Huang H and Spyratos D: Treatment of non-small cell lung cancer (NSCLC). J Thorac Dis 5 (Suppl 4): S389-S396, 2013. 
11. Zarogoulidis P, Huang H, Bai C, Petridis D, Papadopoulou S, Faniadou E, Eleftheriadou E, Trakada G, Cristoforos K, Rapti A, et al: Nab-paclitaxel as first line treatment for NSCLC in elderly patients more than 75 years old. J Cancer 8: 1673-1678, 2017.

12. Tsoulos N, Papadopoulou E, Metaxa-Mariatou V, Tsaousis G, Efstathiadou C, Tounta G, Scapeti A, Bourkoula E,Zarogoulidis P, Pentheroudakis $\mathrm{G}$, et al: Tumor molecular profiling of NSCLC patients using next generation sequencing. Oncol Rep 38: 3419-3429, 2017.

13. Zarogoulidis $P$, Huang $H$, Tsiouda T, Sardeli C, Trakada G, Veletza L, Kallianos A, Kosmidis C, Rapti A, Papaemmanouil L, et al: Immunotherapy 'Shock' with vitiligo due to nivolumab administration as third line therapy in lung adenocarcinoma. Respir Med Case Rep 22: 283-286, 2017.

14. Sapalidis K, Kosmidis C, Michalopoulos N, Koulouris C, Mantalobas S, Giannakidis D, Munteanu A, Surlin V, Laskou S, Zarogoulidis $\mathrm{P}$, et al: Psoriatic arthritis due to nivolumab administration a case report and review of the literature. Respir Med Case Rep 23: 182-187, 2018.

15. Conigliaro T, Boyce LM, Lopez CA and Tonorezos ES: Food intake during cancer therapy: A systematic review. Am J Clin Oncol 43: 813-819, 2020

16. Huhmann MB and Cunningham RS: Importance of nutritional screening in treatment of cancer-related weight loss. Lancet Oncol 6: 334-343, 2005.

17. Segura A, Pardo J, Jara C, Zugazabeitia L, Carulla J, de Las Peñas R, García-Cabrera E, Luz Azuara M, Casadó J and Gómez-Candela C: An epidemiological evaluation of the prevalence of malnutrition in Spanish patients with locally advanced or metastatic cancer. Clin Nutr 24: 801-814, 2005.

18. Xara S, Amaral TF and Parente B: Undernutrition and quality of life in non small cell lung cancer patients. Rev Port Pneumol 17: 153-158, 2011 (In Portuguese).

19. Lis CG, Gupta D, Lammersfeld CA, Markman M and Vashi PG: Role of nutritional status in predicting quality of life outcomes in cancer-a systematic review of the epidemiological literature. Nutr J 11: 27, 2012.

20. Laky B, Janda M, Kondalsamy-Chennakesavan S, Cleghorn G and Obermair A: Pretreatment malnutrition and quality of life-association with prolonged length of hospital stay among patients with gynecological cancer: A cohort study. BMC Cancer 10: 232, 2010.
21. Datema FR, Ferrier MB and Baatenburg de Jong RJ: Impact of severe malnutrition on short-term mortality and overall survival in head and neck cancer. Oral Oncol 47: 910-914, 2011.

22. Van Cutsem E and Arends J: The causes and consequences of cancer-associated malnutrition. Eur J Oncol Nurs 9 (Suppl 2): S51-S63, 2005

23. Szmidt MK, Kaluza J, Harris HR, Linden A and Wolk A: Long-term dietary fiber intake and risk of chronic obstructive pulmonary disease: A prospective cohort study of women. Eur J Nutr 59: 1869-1879, 2020.

24. Mohan A, Singh P, Kumar S, Mohan C, Pathak AK, Pandey RM and Guleria R: Effect of change in symptoms, respiratory status, nutritional profile and quality of life on response to treatment for advanced non-small cell lung cancer. Asian Pac J Cancer Prev 9: 557-562, 2008.

25. Martin L, Birdsell L, Macdonald N, Reiman T, Clandinin MT, McCargar LJ, Murphy R, Ghosh S, Sawyer MB and Baracos VE: Cancer cachexia in the age of obesity: skeletal muscle depletion is a powerful prognostic factor, independent of body mass index. J Clin Oncol 31: 1539-1547, 2013.

26. van Bokhorst-de van der Schueren MA, van Leeuwen PA, Sauerwein HP, Kuik DJ, Snow GB and Quak JJ: Assessment of malnutrition parameters in head and neck cancer and their relation to postoperative complications. Head Neck 19: 419-425, 1997.

27. Van Bokhorst-de Van der Schuer MA, Langendoen SI, Vondeling H, Kuik DJ, Quak JJ and Van Leeuwen PA: Perioperative enteral nutrition and quality of life of severely malnourished head and neck cancer patients: A randomized clinical trial. Clin Nutr 19: 437-444, 2000.

28. Barreira JV: The role of nutrition in cancer patients. Nutr Cancer 1-2, 2020.

29. Inglis JE, Lin PJ, Kerns SL, Kleckner IR, Kleckner AS, Castillo DA, Mustian KM and Peppone LJ: Nutritional interventions for treating cancer-related fatigue: A qualitative review. Nutr Cancer 71: 21-40, 2019.

30. Campbell TC: Nutrition and cancer: An historical perspective. The past, present, and future of nutrition and cancer. Part 2. Misunderstanding and ignoring nutrition. Nutr Cancer 69: 962-968, 2017.

31. Kiss NK, Krishnasamy M and Isenring EA: The effect of nutrition intervention in lung cancer patients undergoing chemotherapy and/or radiotherapy: A systematic review. Nutr Cancer 66: 47-56, 2014.

32. Lindstad T, Jin Y, Wang L, Qu S and Saatcioglu F: STAMPs at the crossroads of cancer and nutrition. Nutr Cancer 62: 891-895, 2010. 